\title{
Post-Soviet Intimacies: An Introduction
}

\author{
Christopher S. Swader ${ }^{1}$ - Vaida Obelene ${ }^{2}$
}

\begin{abstract}
This article frames the "Post-Soviet Intimacies" special issue collection. We begin through briefly using Russia as a special case for the wider Soviet sphere and situating recent Russian developments in sexual politics alongside its internal and external conflicts. Our key interpretive frame is that intimacy politics serve as a master key for understanding political and economic patriarchy. After this, we provide some definitions of our concepts, describe our approach and process of creating the special issue, and introduce important literature which is widely applicable for understanding this theme as a whole. Finally, we briefly introduce the seven articles of this special issue within three wider groupings of Harnessed-, Material-, and Scorned Intimacies. We suggest that readers analyze our contributions from a perspective that situates intimacies as the objects of state and market power, where the linchpin of such power is the patriarchically naturalized pursuit of rule.
\end{abstract}

Keywords Intimacies · Post-communism - Patriarchy · Alternative sexualities · Sexual politics $\cdot$ Rationalization of love

\section{Introduction}

This article is the entry point for reading the "Post-Soviet Intimacies" collection of Sexuality and Culture. We proceed by briefly presenting Russia as a special case for the wider Soviet sphere while situating its recent developments in sexual politics alongside its external and internal conflicts. We suggest that readers consider an

Christopher S. Swader

christopher.swader@soc.lu.se

1 Department of Sociology, Lund University, Box 114, 22100 Lund, Sweden

2 Uppsala Centre for Russian and Eurasian Studies, Uppsala University, Uppsala, Sweden 
interpretive frame whereby intimacy politics serve as a master key for understanding political and economic patriarchy. After this, we offer some definitions of key concepts, the details of our process of creating the special issue and our particular approach, followed by an introduction of important literature useful for a broad understanding of the subject matter. Finally, we briefly introduce the seven articles of this special issue.

Not long ago, the bulk of news headlines from Russia were of a different sort. Only a few years ago came infamous moves against 'gay propaganda', and, before that, the arrest and imprisonment of Pussy Riot band members. Both of these events are examples of the state's tightening of the content and rights regarding the public information space. The Pussy Riot prosecution occurred because women directed their voices directly against the alliance between Russian orthodoxy, the Russian state, and the so-called 'traditional' patriarchical values that sanctify this union. Moreover, they stood in the face of a gender expectation that they, as women, had no political role but to highlight the masculinity (and thereby, the authority) of the president. Gay propaganda legislation similarly denies a public platform to anyone except male heterosexuals. Straight men may oppose the regime, but they tend to do so within the traditional ideological frame. Female and gay opposition are each doubly subversive because they challenge the very legitimacy of the state's 'traditional Russian' (patriarchical) script. In this sense, the gay propaganda and Pussy Riot episodes each connect directly to Russia's current internal (in relation to the opposition) and external (the crisis in Ukraine) conflicts. The state's ideology campaign is largely successful because its central tenet, of values purity in traditional masculine form, is accepted even by the majority of those who oppose state policy. Through this it becomes clear why Pussy Riot and Russia's gays and lesbians have not received the support of the majority of those who otherwise oppose 'Putin's Russia'. Post-Soviet Intimacy, gender, and sexuality, in this context, are quintessentially political because their right to be so is politically and culturally denied.

\section{Our Approach}

Intimacy is fundamentally impacted by cultural, political, and economic change. Its forms are modified over the long term, sometimes gradually but also suddenly as a result of breakthroughs and upheavals. The period of decay before the fall of the USSR and the tumultuous two and a half decades that followed hardly constitute one of social stability by any standard. How has intimacy in Post-Soviet societies been both transformed and preserved as a result of Soviet legacies and more recent developments across the spheres of culture, economics, and politics?

The term "intimate" may be used to connote a sexual relationship. However, an emphasis on the emotional aspects of intimacy locates this concept in a distinct, yet overlapping, domain from sexuality. A model for this is Lynn Jamieson's (1998) definition of "disclosing intimacy", which is a form of "being close" that emphasizes knowing and understanding one another, which she distinguishes from both practical "love and care" and from physical intimacy. We also employ such a 
definition of intimacy, one that is broader than sexuality, in order to explore the largest possible range of social change effects. We therefore refer to intimacy as a wide range of practices involving "being close", whether emotionally, physically, or romantically. Thereby, intimacy itself is a historically contingent and multiplex concept. In view of the normative-hegemonic dimensions of intimacy and the variety of subjective feelings and the relationships to which it can apply, it only makes sense to speak of intimacies in the plural.

Social change is no less complex. Especially in societies turned upside down in the 1990s, where no area of social life was left untouched, where profound feelings of disorientation, demoralization, and culture shock pervaded many people's everyday lives, even a broad focus on the shift in intimacies leaves open the question of which causes of social change upon which to focus.

Yet what advantage do we gain through the "Post-Soviet" category? These societies shared a uniform Stalin and post-Stalin-era framework of repressed sexualities/intimacies and were subjected to a doctrine of love designed to project interpersonal intimate feelings towards the regime. The severity of this intimacy regime, represented by a catchphrase claiming the lack of sex in the USSR, makes these societies unique. Following the collapse of the USSR, the public discourse on sexuality was substantially liberalized. In the private sphere, a sort of 'sexual revolution' took place. Sex came out of the closet, but also in a way that embodied moral panic, 'Westernization,' commercialization, and deromanticization (Kon 1995). Our focus on the Post-Soviet space highlights the need for acknowledging the particularity of this experience, and the relations between intimacy and social change in this region also serve as a 'natural laboratory'.

With the collapse of the Soviet regime, intimacies, in some forms but not others, re-entered the public sphere. At the same time, religious re-traditionalization, political instability, economic troubles, and commercialization have each affected intimacy in various ways. In this context, we ask the following questions: Which are the continuities and disjunctures that link and separate Post-Soviet Intimacies to and from their Soviet roots? How have romance, sexuality, and dating become affected by the rapid rise of a culture promoting the consumption of luxuries? How have changing power relationships and inequality affected understanding and practices of intimacy? In which ways have political, religious, and even technological change released or stymied the 'coming out' of suppressed sexualities? How are shifts in the meaning of intimate relationships reflected in language?

All in all, we make sense of the complexities/intersectionalities of intimacies as resurfacing, emerging and declining amid the transformations shaping the PostSoviet space. While an 'intimacies' approach can lead to the ideographic and fascinating study of disparate rich subjective phenomena, we sought to integrate both spheres and time. In terms of spheres, we investigate the ways that cultural, political, and economic dynamics overlap in shaping intimacy. In terms of time, we investigate the historical continuities and disruptions that connect our intimacies to the Soviet era. 
In particular, we suggest that readers analyze our contributions from a perspective that makes intimacies (whether love, sex, family) the objects of state and market power, where the linchpin of such power is a hierarchical, patriarchically naturalized, pursuit of rule. Contestations of this rule of course occur, but these often make use of the same core hegemonic language, one based on binary domination, whether or not the roots of this are self-identified as Soviet, pre-Soviet, or a Post-Soviet legacy.

\section{The Process}

The construction of this special issue was intentionally a long-term development. We started with an open call for abstracts in January 2013, and we arranged a frame to support the authors' development of these into full articles over the following 2 years. In addition to peer reviewer input, the editors themselves have seen no less than four versions of each paper.

It is natural in the selection and development of a project that certain areas become better covered than others. Nonetheless, it is worth mentioning this issue's gaps. First, our geographical representation only covers European Post-Soviet societies. We received precious few contributions on Central Asia-these did not make it through the review process-and none covering the Caucasus. Whether this lack of submissions represents academic cultural hierarchies, social networks, or disparate local research foci is an open question.

Therefore this work is 'Soviet' only in a limited sense. It is more Russiacentric than we would prefer, but the articles nonetheless address themes having wider salience during Soviet and Post-Soviet years. Sexuality is as contested in central Asia and the Caucasus as it is in Western Soviet countries. Similarly, state control over intimacy may bridge the two eras in a somewhat uniform manner. On the other hand, economic developments were far more disparate because of different economic models, from state capitalism, to varieties of socialism, to the new EU states. In addition, the cultural and political digestion of the Soviet legacy is clearly among the biggest points of contention between Post-Soviet societies, visible within the Ukraine conflict but also extending to most former Soviet states. This is also clear within internal Russian developments, such as the rehabilitation of Stalin and the recent whitewashing of Soviet state crimes within the "Perm-36" Gulag museum. However, it is precisely because of this differentiated handling of Soviet symbols across different societies that the parallels in state and cultural habitus regard population control, family and 'traditional' orientations stand out. This issue hardly presents a complete picture (if one were even possible) of intimacy topics in the societies it represents; nor is a particular subfield saturated. Yet this collection is indeed unique for its thematic and geographical breadth, its attempt to integrate the political, economic, and cultural fields, and its orientation on socio-historical changes and continuities. 


\section{Further Reading}

The 'intimacies' theme is situated in the broader fields of gender and family studies. Research conducted under these headings is diverse and numerous, if nonetheless fragmented, in the former USSR (see, for example, the comprehensive bibliography of Zirin et al. 2007). Yet it is recognized that scientific knowledge in Post-Soviet space in these fields considerably declined as of late and "has drastically fallen behind transformations in real life" (Tartakovskaya and Irina 2010). Others have concluded that the field of sexuality studies in (and about) CEE is in its infancy" (Kulpa and Mizielińska 2011). Studies of sexuality and love with explicit theoretical and analytical orientations are especially scarce.

Each of our seven published articles employs a relevant coverage of and communication with the key scholarship in its field. To repeat this work here would be redundant. It would also be unfeasible to give a full review of other literature on themes as diverse and expansive as those concerning intimacy in the Post-Soviet world. Such a task could easily consist of several volumes. Instead, we provide our readers with a few additional reading recommendations, not necessarily cited in our articles, which we find useful for understanding the interplay between the topics herein.

Readers unfamiliar with the Soviet and Post-Soviet gender order could certainly start with Sarah Ashwin's book, Gender, State and Society in Soviet and Post-Soviet Russia (2000). It is a formidable collection on the transformation from Soviet to Post-Soviet gender ideals in Russia. Another good background work is research conducted on the transformation of Russian families and marriages, Marriages in Russia: Couples during the Economic Transition (Vannoy et al. 1999). Based on survey data collected in the 1990s in Pskov, Saratov, and Moscow, it deals with the interplay between patriarchical gender norms, marital quality, domestic violence, socio-economic status, and alcohol abuse. A more recent account dealing with Eastern European families, with a strong sensitivity toward gender norms and the interactions between state policy, ideology, and everyday life, is the edited monograph And They Lived Happily Ever After? Norms and Everyday Practices of Family and Parenthood in Russia and Eastern Europe (Carlbäck et al. 2012). We would recommend a fine introduction into Soviet and Post-Soviet sexuality by reading some of the groundbreaking work of Russian 'sexologist' Igor Kon, such as Sexual revolution in Russia. From the age of the czars to today (1995). The importance of Kon's work prompts us to highlight it now, despite multiple references to it in the individual articles.

Much of the intimacies research on post-Soviet societies has been inadequately connected to neighboring and relevant contexts of social change, such as transformations of economic and political power. Furthermore, the available English language studies of post-communist intimacies are strongly embedded within the context of a "Western" and "Eastern" divide. For example, Sexuality and Gender in Post-communist Eastern Europe and Russia (Stulhofer and Sanfort 2005 ) is among the first major works concerned with issues of sexuality in the postcommunist space. The collection may be characterized as trying to avoid employing 
a Western lens into the study of post-communist sexualities while indirectly grappling with the question of whether the East will come to mirror the West. As an antidote to this, scholarship such as De-centering Western Sexualities: Central and Eastern European Perspectives (Kulpa and Mizielinska 2011) considers how analyses of queer movements in the West are not immediately applicable in the East. It challenges hegemonic 'West versus the rest' sexuality discourses' undifferentiated applications by unpacking the grey area in between: the neighboring Central and Eastern Europe. It argues for a more nuanced, non-binary, understanding of sexualities.

Further within the fields of sexualities and sexual politics in Central and Eastern Europe, a number of texts deserve special mention. Only last year, Francesca Stella has published Lesbian Lives in Soviet and Post-Soviet Russia: Post/Socialism and Gendered Sexualities (2014). This book is unique as an ethnographically informed account of same-sex sexualities of women in Russia. The work is carefully researched and aware of and cautious in situating itself regarding 'Western' intellectual accounts on Eastern sexuality. Her fieldwork encompasses multiple geographical regions in Russia and creates bridges between the Soviet era and the present. Furthermore, Dan Healy has published a multitude of intriguing historical works uncovering the history of sexualities in Russia, especially during the Soviet Period. An example would be his recent chapter entitled, "The sexual revolution in the USSR: dynamic change beneath the ice" (Healy 2014). He explains that indeed there was a sexual revolution in the late Soviet period, but it was one with very different characteristics from its 'parallels' in the West during the same period.

\section{Approach: Integrated Spheres and Social Change}

Two further pieces of scholarship stand out for exemplifying the style of analysis we find most ambitious and advantageous for this theme. The first would be Elena Gapova's (2004) "Conceptualizing Gender, Nation, and Class in Post-Soviet Belarus". This work frames gender as a central concept for explaining both 'class' and 'the national'. She explains how "national projects, as well as class ones, demand specific gender arrangements and invoke particular symbolic representations of men and women" (Gapova 2004: 4). We see a complementary angle within Nida Vasiliauskaité's (2013) "Sexual nationalism: 'I love Lithuania", where she writes that love and sexuality, in their sexist and heterosexist forms, are key for bonding individuals politically to an ethno-nationalist state. In these two works lie an integrative frame through which it is possible, and highly beneficial, to view this edition's contributions. In particular, it is necessary to see the synchronicity of state power and gender order. Herein, control over intimacy and love is a means of upholding patriarchical rule, both politically and economically.

It is worth noting that, despite this state-control line of academic argumentation, the re-'traditionalization' of values was not initially a state-directed project in the early 1990s. The resurrection of religiosity and religious institutions and personal neo-identifications with pre-Soviet legacies as a result of the collapse of the USSR helped push 'traditional values' to the forefront. However, the reality was a 
continued active involvement of women in the labor market despite this growing conservativism in values.

In the Russian case, re-traditionalization first became a state project as a result of a need to spur fertility because of declining birth and marriage rates. However, it soon became a symbolic linchpin for those searching for a way to unite national and ethnic identities behind a powerful state. This process results in an ideologically based exclusion of so-called 'non-fertile' sexualities from the public sphere in a manner similar to the Soviet era. At the same time, some of these sexualities have become targets, portrayed as representing foreign values.

Furthermore, it can be observed that the commercial realm interacts with the state interest in largely complementary ways. The new public display of heterosexuality, at first at least partially a bottom-up reaction to sexual liberalization, quickly became driven by marketing and advertisement logics and found its payouts by aligning with the state and popular interest in portraying traditional heteronormativity, largely through exploiting the image of the female body.

\section{Our Contributions}

The articles in this edition fit into three groups: (1) Harnessed Intimacies: Political Manipulations of Sex; (2) Material Intimacies: Rationalization and Consumption of Love; and (3) Scorned intimacies: Sexuality as Culturally and Structurally Rejected. Within each group, we highlight the connection of each article to the issue while summarizing its thesis, data, findings, and strengths.

\section{Harnessed Intimacies: Political Manipulations of Sex}

The two articles in this section focus on the recent event of criminalizing "propaganda for non-traditional sexual relations" and the surrounding Anti-LGBT campaign in Russia in order to investigate how state power seeks to bring "alternative" sexualities under control or at least push them out of the public sphere. The contributions in combination give added value through their different angles. The Persson article deals with the public realm in relation to the campaign, while Soboleva and Bakhmetjev address its private, grassroots ramifications. These articles are notable in seeing alternative sexuality as an political endeavor and explore the ramifications of its visibility at different levels of discourse.

According to Persson's piece, visibility is central to the "battle of belonging". It is through control of the mainstream media that state power in Russia seeks to contest the visibility of alternative sexualities, which prompts the author to conduct an analysis of articles published in the mainstream media during the anti-LGBT campaign. The article, the study of "a hegemonic grammar for seeing and hearing non-heterosexuality", reveals the components in the dominant narrative used to contest the belonging of non-heterosexuals to the Russian nation. According to this narrative, the rights of LGBT people would threaten the survival of the nation, impose values and lifestyles of an influential minority on the majority, and emulate the failed Western modernity. In a step that is important both in its methodological 
subtlety and for praxis, Persson also identifies "moments of disruption" of the dominant narrative and highlights these as tactical entry points to redirect the discourse in a more LGBT-friendly direction.

Soboleva and Bakhmetjev study how homosexual and bisexual people explain and react to the anti-LGBT campaign in Russia in 2012-2013. The authors have collected an impressive set of in-depth problem-centered interviews. They reveal different explanatory narratives, which interpret the campaign as a political communication project of state power that was not targeted at the LGBT community per se. Rather, it has instrumentalized LGBT issues, for example to push its agendas against "pro-Western" forces and values. A notable and counterintuitive finding of this analysis is the self-blame, escapism, and moral suffering that authors reveal in the structure of the narratives of homosexual and bisexual people, despite their understanding of the politics behind the campaign.

\section{Material Intimacies: Rationalization and Consumption of Love}

The articles in this section deal with the recent historical development of a more individualized, rationalized, consumption-oriented culture and the links of these developments to intimacy. Understanding this 'modern' movement and its economic-rational dimensions, occurring alongside a campaign of re-traditionalization and a politically resurgent authoritarian nationalism, is crucial and too often left aside in studies of intimacy. Each of the articles shares a common thread through the 'rationalization' theme: Temkina and Zdravomyslova identify it as emergent within the Post-Soviet generation's sexuality scripts, Swader and Vorobeva see evidence for it among the compensated daters in more economically developed cities, and Lerner sees it as the core of an emotional capitalism being contested by Russian and Soviet understandings of love.

Based on biographical interviews with urban middle-class women, Temkina and Zdravomyslova analyze changes in the organization of sexual life among Russian women and describe the sexual scripts that characterize different generations. Their analysis shows that women of the Soviet generations are oriented towards pronatal, romantic and friendship scripts of sexual relationships, while the women of the PostSoviet generation orient towards two new-hedonistic and instrumental—scripts. In the instrumental script, sex is described as economic exchange, and profit and consumption are the drivers of the relationship. In the hedonistic script the sexual desire is a "natural drive"; sex is for pleasure and is distinct from love. These two scripts are a novelty "seldom found" in the accounts of the Soviet generations, and this novelty represents a "rationalization trend in sexual life". This article offers a rich analysis of the impact of economic and cultural change upon intimate lives.

Swader and Vorobeva offer a further contribution to the topic of material intimacies. Theirs is a focus on compensated dating defined as receiving gifts for sex. The paper is a quantitative analysis of comparative survey data with women and men collected in the three capital cities of Moscow, Kyiv and Minsk. They identify a differentiation in the motives of those who receive gifts in exchange for sex. Namely, Muscovites and those from Kyiv appear to have more instrumentalrational motives and take part in the practice as a means of enhancing status; in 
contrast, compensated dating in Minsk was more linked to material survival. Despite these rationalization trends linked to economic development, however, the authors detect no resulting change in fundamental relationship values, such as love. The paper may be seen as identifying a rationalization trend, but it also demonstrates some of the resilience of 'love' in the face of such changes.

Lerner's article on the meaning of love explores the contemporary emotional culture in Russia and focuses on the clash between the Western "therapeutic model" and its counterpart in "emotional socialism." The article is based on the analysis of TV shows, series and cinema productions that were analyzed within the study over a period of 8 years. While revealing complex interplays between competing emotional cultures, the author considers four different Post-Soviet manifestations of love, including a relationship involving well-being without love. Such a 'relationship' is neither psychologized nor therapeutic, nor is there love, but "only hopeless and spiritless well-being". Lerner's article reveals the complex tension between the pulls of a rationalized 'Western' "emotional capitalism's" modifications of love and the historical and cultural energies of an "emotional socialism" that resists it.

\section{Scorned Intimacies: Sexuality as Culturally and Structurally Rejected}

The two articles in this section are concerned with disqualifications from intimacy, about unequal access to and eligibility for intimacy. However, unlike the section on "harnessed intimacies", scorned intimacies tend to be hidden, silent, and structural. As such, they for the most part do not find themselves as the objects of state posturing, although they are certainly impacted by state and economic structures. Sumskiene and Orlova deal with the taboo subject of intimacy among those with mental disabilities, rejected by culture and the state, while Jurkane-Hobein assesses the self-rejection resulting from personal mismatches to social norms surrounding intimacy.

In using the Lithuanian case to inform on wider Soviet/Post-Soviet trends, Sumskiene and Orlova's inquiry into sexuality and reproduction among people, especially women, with intellectual disabilities in 'care' institutions ventures into a challenging and under-researched area. The article is based on interviews with experts working in international disability and human rights organizations and on relevant literature. Bringing together these perspectives, the authors elucidate the "total institution" exemplified by these care institutions, which have remained largely inert in the years after the Soviet collapse. The residents of these institutions are constructed as "unwanted people" with no sexual rights but also no protection from sexual and bodily violence, their lives are described in penal terms as a "life sentence", and they endure a constant inhumane treatment. In describing the approaches of the institutions towards the sexual rights of the intellectually disabled, the authors explore links to, and stagnation since, the Soviet period and note the lack of commitment at all levels to even discuss the sexual and reproductive rights of the intellectually disabled in these societies.

Jurkane-Hobein's article is based on in-depth interviews with Latvian women and men of various ages having long-distance relationship experience, and it details 
how their relationship conceptions are generation- and gender-specific. Five key relationship norms are introduced that have relevance for the private- versus collective-interest dimension. Moreover, the author shows how these norms cause complications to the extent that individuals altogether "disqualify" themselves from the relationships in question. This article's intergenerational material offers promising insight into social change. For instance, "the paternalistic state during the Soviet period and the current neo-liberalist state have constructed different norms, which have a differentiated influence" on (long-distance) relationship maintenance. One of these is the socialist-era norm of "silent intimacy", and intriguingly, Jurkane-Hobein sees evidence for its dissolution in lieu of Jamieson's potentially more empowering "disclosing intimacy".

We conclude with a welcome to explore these seven contributions and a hope that this collection will assist in inspiring further research on Post-Soviet Intimacies in a way that is sensitive to social change, seeks to integrate the spheres of politics, culture, and the economy, and serves to further open up research into the previously taboo.

Acknowledgments We have received institutional support from the Rijkbanken Jubilaemsfond and the Uppsala Center for Russian and Eurasian Studies (Uppsala University) for a workshop that supported the development of these manuscripts. We would also like to thank the Uppsala Forum and the Swedish Institute for supporting the mobility of the authors in connection to this project. Claes Levinsson and Bo Lewin were supportive of this project's development, and we also benefited from significant intellectual contributions from Nida Vasiliauskaite, Alexander Kondakov, Varvara Chumakova, Johan Matz, and My Lilja. Finally, this journal's editor and editorial team, and above all, our authors, deserve our enormous gratitude for their patience and thoughtful contributions.

\section{References}

Ashwin, S. (2000). Gender, state and society in Soviet and Post-Soviet Russia. New York: Routledge.

Carlbäck, H., Gradskova, Y., \& Kravchenko, Z. (Eds.). (2012). And they lived happily ever after? Norms and everyday practices of family and parenthood in Russia and Eastern Europe. Budapest: CEU Press.

Gapova, E. (2004). Conceptualizing gender, nation, and class in Post-Soviet Belarus. In C. Nechemias \& K. Kuehnast (Eds.), Post-Soviet women encountering transition: Nation building, economic survival, and civic activism. Washington, DC/Baltimore: Woodrow Wilson Center Press/Johns Hopkins University Press.

Healy, D. (2014). The sexual revolution in the USSR: Dynamic change beneath the ice. In G. Hekma \& A. Giami (Eds.), Sexual revolutions (pp. 236-248). Basingstoke: Palgrave.

Jamieson, L. (1998). Intimacy: Personal relationships in modern societies. Cambridge: Polity.

Kon, I. S. (1995). Sexual revolution in Russia. From the age of the czars to today. New York: Free Press.

Kulpa, R., \& Mizielinska, J. (Eds.). (2011). De-centring western sexualities: Central and Eastern European perspectives. London: Ashgate.

Stella, F. (2014). Lesbian lives in Soviet and Post-Soviet Russia: Post/socialism and gendered sexualities. New York: Palgrave.

Stulhofer, A., \& Sanfort, T. (Eds.). (2005). Sexuality and gender in post-communist Eastern Europe and Russia. New York: The Haworth Press.

Tartakovskaya, I. (2010). Gender relations in the private sphere: Post-Soviet transformations of family and intimacy (Introduction). Laboratorium, 2(3), 12-18.

Vannoy, D., Rimashevskaya, N., Cubbins, L., Malysheva, M., Meshterkina, M., \& Pisklakova, M. (1999). Marriages in Russia: Couples during the economic transition. Westport: Praeger.

Vasiliauskaitè, N. (2013). Seksualinis nacionalizmas: 'Aš myliu Lietuvą' (Sexual nationalism: 'I love Lithuania'). Politologija, 1(69), 62-87. 
Zirin, M., Livezeanu, I., Worobec, C. D., \& Farris, J. P. (Eds.). (2007). Women and gender in Central and Eastern Europe, Russia, and Eurasia: A comprehensive bibliography volumes I and II. New York: The Association for Women in Slavic Studies. 